\title{
Desenvolvimento de um software livre para análise de imagens de microscopia ótica
}

\section{Free software development for optical microscopy image analysis}

\author{
DOI: 10.46814/lajdv3n3-044
}

Recebimento dos originais: 01/052021

Aceitação para publicação: 31/06/2021

\author{
Diego da Silva Sales \\ Doutor em Engenharia e Ciência dos Materiais \\ Instituto Federal Fluminense Campus Campos Guarus \\ Av. Souza Mota, No 350 - Parque Fundão, Campos dos Goytacazes - RJ, 28060-010 \\ E-mail: dsales@iff.edu.br \\ Angelus Giuseppe Pereira da Silva \\ Doutor em Ciências Técnicas \\ Universidade Estadual do Norte Fluminense Darcy Ribeiro \\ Av. Alberto Lamego, № 2000 - Parque Califórnia, Campos dos Goytacazes - RJ, \\ 28013-602 \\ E-mail: angelus@uenf.br

\section{Camila Mendonça Romero Sales} \\ Doutora em Engenharia e Ciência dos Materiais \\ Instituto Federal Fluminense Campus Campos Centro \\ R. Dr. Siqueira, No 273 - Parque Dom Bosco, Campos dos Goytacazes - RJ, 28030-130 \\ E-mail: camila.sales@iff.edu.br
}

\section{RESUMO}

O uso das câmeras digitais acopladas a microscópios óticos impulsionou o uso de softwares para análises de imagens. Este trabalho teve como objetivo desenvolver um software de análise de imagens, denominado Goitacá, que incorporou os principais recursos dos softwares de análise de imagens de distribuição livre e proprietária. Além destes recursos, destacam-se a vídeo microscopia, abrangendo amplo número de modelos de câmeras digitais, inclusive de alta definição e as medições de comprimento entre dois pontos e áreas de região. O Goitacá foi desenvolvido para plataforma Windows, contudo, os recursos utilizados em seu desenvolvimento são multiplataforma, o que lhe permite maior flexibilidade para inclusão de novos recursos e adaptações para outras plataformas. Para validar o software proposto, uma versão alfa foi distribuída para testes de usuários internos. Para testes de maior envergadura, uma versão beta foi distribuída no repositório de software livre "source forge" para usuários externos. Cumpre-se o objetivo do trabalho, ao passo que se apresenta um produto completo com as características almejadas, em que a metodologia de validação foi corretamente conduzida, de modo a confirmar a eficácia da ferramenta.

Palavras chave: Software livre, Análise de imagens, Microscopia ótica, Vídeo microscopia.

\section{ABSTRACT}

The use of digital cameras attached to optical microscopes has boosted the use of software for image analysis. This work aimed to develop a software for image analysis, named Goitacá, which incorporated the main resources of image analysis softwares of free and proprietary distribution. 
Besides these resources, video microscopy stands out, covering a large number of digital camera models, including high definition, and measurements of length between two points and region areas. Goitacá was developed for the Windows platform, however, the resources used in its development are multiplatform, which allows greater flexibility for the inclusion of new resources and adaptations for other platforms. To validate the proposed software, an alpha version was distributed for internal user testing. For more extensive testing, a beta version was distributed on the free software repository "source forge" for external users. The objective of the work has been met, in that a complete product with the desired characteristics has been presented, in which the validation methodology was correctly conducted, in order to confirm the effectiveness of the tool.

Keywords: Free software, Image analysis, Optical microscopy, Video microscopy.

\section{INTRODUÇÃO}

O microscópio ótico é uma ferramenta largamente utilizada na pesquisa e desenvolvimento de materiais, seu uso tornou-se ainda mais intenso com o surgimento da vídeo microscopia. O microscópio ótico permaneceu afastado da área computacional por um longo tempo. A priori, as imagens eram visualizadas pelos operadores de microscópio ótico diretamente nas lentes dos microscópios e registradas em filme de celulóide. Estes microscópios se modernizaram com a difusão das câmeras digitais, que substituíram as câmeras com filme de celulóide. A partir do uso das câmeras digitais, a transferência, assim como a análise quantitativa das imagens, através das técnicas de computação gráfica, foi facilitada e este fator impulsionou o uso de softwares para estes fins (FAZANO, 2005; FERNANDES et al., 2012; MENDES, 2005; NOGUEIRA, 2013).

Portanto, a modernização do microscópio ótico, segue duas tendências: a automatização do equipamento e a análise quantitativa das imagens visualizadas por ele.

A automatização do equipamento, de maior relevância, ocorre com o microscópio ótico acoplado a uma câmera digital conectada a um microcomputador. Este processo é denominado vídeo microscopia. Por meio dele as imagens estáticas (fotografias) e dinâmicas (vídeos) são capturadas e armazenadas em um microcomputador (FERNANDES et al., 2012; LASEROPTICS, 2014).

A análise quantitativa consiste em obter informações numéricas da imagem. Para isso, é necessária uma ferramenta eficiente capaz de transformar em números, as características dos elementos que formam a imagem. Frequentemente, esta ferramenta está atrelada a um software de análise de imagem (DIAS, 2008).

Os softwares de análise de imagem são ferramentas que variam bastante suas características. Estes softwares têm ampla aplicabilidade em diversas áreas da ciência como: metalurgia, biologia e medicina. Cada área possui sua própria especificidade, além das características comuns a todos os softwares de análise de imagem. Na internet é comum encontrar estes softwares com distribuições 
livres e proprietárias. Há ainda aqueles que são comercializados pelos fabricantes dos microscópios e de câmeras digitais para microscópios (AMSCOPE, 2014; FAZANO, 2005; LEICA MICROSYSTEMS, 2014; NIKON INSTRUMENTS, 2014).

A pesquisa bibliográfica realizada para este trabalho identificou um nicho acadêmico ainda pouco explorado na ciência e engenharia de materiais, que é uma ferramenta que congregue as principais análises de imagens, e ainda se beneficie das facilidades de ter sua distribuição livre. Intenciona-se com esta pesquisa desenvolver para academia o ferramental necessário para realização de diversas análises de imagens em um único software, sem custos para o pesquisador.

O objetivo deste trabalho é desenvolver um software de análise de imagens na linha de automatização do microscópio ótico. O software proposto foi denominado Goitacá e inclui os principais recursos dos softwares de análise de imagens de distribuições livres e proprietárias, além de recursos de vídeo microscopia, abrangendo um amplo número de modelos de câmeras digitais e de medições de comprimento entre dois pontos e áreas de região.

Este trabalho apresenta no item 0 a metodologia de desenvolvimento do software proposto, contendo os recursos utilizados em seu desenvolvimento, assim como as funcionalidades implementadas na primeira e segunda fase do desenvolvimento. No item 0 é realizado uma apresentação dos principais recursos do software proposto implementados nas duas primeiras etapas. Por ultimo, no item 0 , são descritas as conclusões quanto aos objetivos e aos trabalhos realizados.

\section{METODOLOGIA}

O Goitacá foi desenvolvido para plataforma Windows, entretanto, os recursos utilizados em seu desenvolvimento, o framework Qt e a biblioteca OpenCV, são multiplataforma, o que flexibiliza a inclusão de novos recursos e adaptações para outras plataformas.

Para validação do Goitacá, versões alfa e beta foram distribuídas para testes. A versão alfa foi distribuída para a realização de testes por usuários internos. Já a versão beta foi aquela aprovada na avaliação interna (versão alfa), sendo posteriormente distribuída aos usuários externos para testes de maior envergadura, através do repositório de software livre "source forge" no endereço "https://sourceforge.net/projects/goitacaeq/".

\subsection{FUNCIONALIDADES DO SOFTWARE}

O software proposto foi desenvolvido em três etapas, as duas primeiras fazem parte do escopo deste trabalho, a terceira engloba diversas análises estereológicas em microestruturas e será abordada em outro trabalho. 
Para a definição da interface, softwares livres e proprietários do gênero foram avaliados. Considerou-se a similaridade da interface destes softwares, a fim de facilitar a assimilação de novos usuários (AMSCOPE, 2014; IMAGEJ, 2014; LEICA MICROSYSTEMS, 2014; NOGUEIRA, 2013).

Na primeira etapa do software desenvolvido foram implementadas as funcionalidades descritas no Quadro 1. Observa-se também neste quadro uma breve descrição de cada funcionalidade do Goitacá.

Quadro 1 - Funcionalidades desenvolvidas na primeira etapa do Goitacá.

\begin{tabular}{|l|l|}
\hline Funcionalidades & Descrição \\
\hline Abrir imagem & abre imagem nas extensões "png", "jpg", "jpeg", "bmp" e "goi" \\
\hline Abrir vídeo & $\begin{array}{l}\text { abre vídeo na extensão "avi", com recursos de voltar, avançar e pausar para permitir } \\
\text { maior precisão na captura da imagem }\end{array}$ \\
\hline Salvar/ Salvar como & $\begin{array}{l}\text { salva imagem com diversas camadas na extensão "goi" para permitir editar, excluir } \\
\text { e ocultar anotações gráficas na imagem }\end{array}$ \\
\hline Exportar para & exporta imagens nas extensões "png", "jpg", "jpeg" e "bmp" \\
\hline Carregar câmera & carrega câmera para captura de tela e gravação de vídeo \\
\hline $\begin{array}{l}\text { Iniciar/Finalizar gravação na } \\
\text { câmera }\end{array}$ & inicia e finaliza a gravação de vídeos da câmera \\
\hline Capturar tela & captura tela atual da câmera ou do vídeo carregado \\
\hline Zoom & amplia / reduz a imagem \\
\hline Transformação & gira 90 para direita, 90º para esquerda, inverte verticalmente e horizontalmente \\
\hline Cortar & corta e cria nova imagem \\
\hline Inverter & inverte imagem binarizada \\
\hline Refazer e Desfazer & refaz e desfaz as alterações na imagem \\
\hline Incluir anotações gráficas & $\begin{array}{l}\text { inclui anotações gráficas na imagem como círculos, triângulos, quadrados, } \\
\text { losangos, pentágonos, hexágonos, linhas retas, linhas livre, setas e textos }\end{array}$ \\
\hline Formatar anotações gráficas & $\begin{array}{l}\text { formata cor, largura, tipo de fonte, cor de fonte e estilo de fonte das anotações } \\
\text { gráficas na imagem }\end{array}$ \\
\hline Posição X e Y & exibe as coordenadas X e Y da imagem \\
\hline Dimensão & exibe as dimensões em pixel da imagem \\
\hline Tamanho & exibe o tamanho da imagem \\
\hline $\begin{array}{l}\text { Miniaturas na barra de } \\
\text { snapshot }\end{array}$ & $\begin{array}{l}\text { abre as miniaturas de imagem da barra de snapshot para visualizar diversas imagens } \\
\text { ao mesmo tempo }\end{array}$ \\
\hline
\end{tabular}

As funcionalidades que foram acrescentadas na segunda etapa do software são basicamente de edição de imagens, estas funcionalidades com suas respectivas descrições são apresentadas no

Quadro 2.

Quadro 2 - Funcionalidades desenvolvidas na segunda etapa do Goitacá.

\begin{tabular}{|l|l|}
\hline Funcionalidades & Descrição \\
\hline Ajustes & ajusta brilho e contraste da imagem \\
\hline Filtros & aplica filtros para aguçar, suavizar, escala de cinza, erodir e dilatar \\
\hline Segmentações & aplica a segmentação de binarização, limiarização por binarização \\
\hline Medições & mede ângulos entre retas, área de região e comprimento entre dois pontos \\
\hline Operações algébricas & soma e subtrai imagens, inclusive de tamanhos e tipos diferentes \\
\hline
\end{tabular}




\section{APRESENTAÇÃO DO SOFTWARE}

Nesta apresentação, além da interface, foram evidenciados os recursos de vídeo microscopia, anotações gráficas, segmentações, escala e medições. Cabe salientar que muitos recursos desenvolvidos no software não serão aqui apresentados.

\subsection{INTERFACE DO SOFTWARE}

A interface do Goitacá foi desenvolvida com base em duas tendências: simplicidade e intuitividade. Com a simplicidade, manteve-se na área de trabalho o menor número de funcionalidades visíveis. Já com a intuitividade, buscou-se localizar com o mínimo de esforço, por parte do usuário, os recursos almejados.

Esta interface é composta de barra de menu, barra de ferramentas, barra de status, painel lateral esquerdo, painel de snapshot e área de trabalho, sendo ilustrada na Figura 1. Este padrão é utilizado por diversos softwares do gênero (AMSCOPE, 2014; FAZANO, 2007; IMAGEJ, 2014; LEICA MICROSYSTEMS, 2014; NOGUEIRA, 2013).

Figura 1 - Interface do software Goitacá.

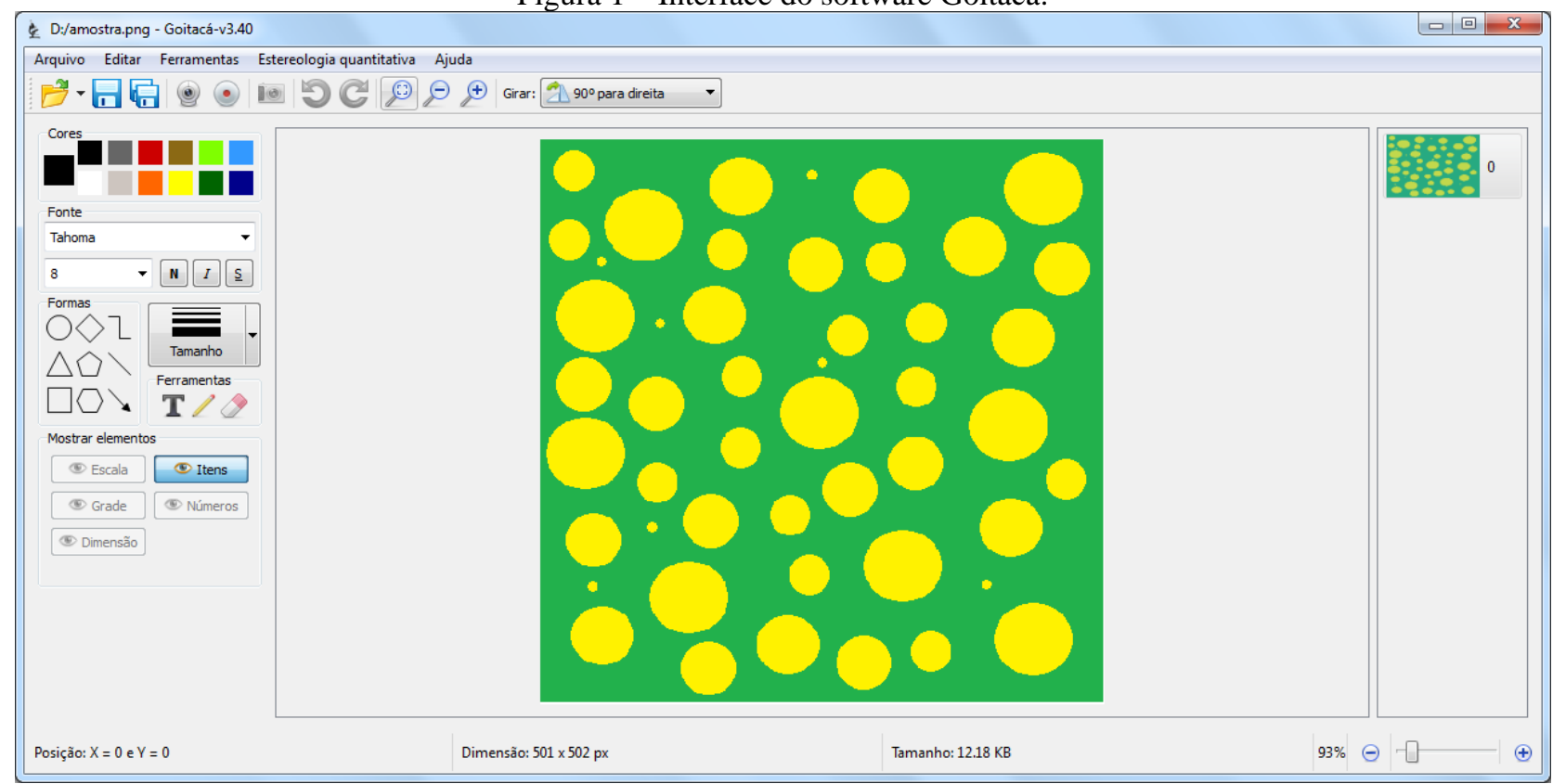

A barra de menus foi dividida em cinco menus principais, sendo eles Arquivo, Editar, Ferramentas, Estereologia e Sobre. Cada menu principal agrupa submenus relacionados. O Quadro 3 apresenta os menus principais e seus respectivos submenus. 
Quadro 3 - Composição da barra de menus do Goitacá.

\begin{tabular}{|l|l|}
\hline Menu Principal & Submenu \\
\hline Arquivo & $\begin{array}{l}\text { Abrir (Imagem e Vídeo), Salvar, Salvar como, Exportar para, Câmera (Carregar, } \\
\text { Iniciar/Finalizar gravação e Resolução), Capturar tela e Sair }\end{array}$ \\
\hline Editar & $\begin{array}{l}\text { Transformação ( } 90^{\circ} \text { para direita, 90 para esquerda, Inverter horizontalmente e Inverter } \\
\text { verticalmente), Zoom (Normal, Reduzir e Ampliar), Cortar, Inverter, Refazer e Desfazer }\end{array}$ \\
\hline Ferramentas & $\begin{array}{l}\text { Ajustes (Brilho e Contraste), Filtros (Aguçar, Suavizar e Escala de cinza), Morfologia } \\
\text { matemática (Erodir e Dilatar), Segmentação (Binarizar e Limiarizar), Escala, Medições } \\
\text { (Ângulo, Área de região e Comprimento entre dois pontos) e Operações algébricas (Soma e } \\
\text { Subtração) }\end{array}$ \\
\hline Estereologia & $\begin{array}{l}\text { Grade (Linhas horizontais, Linhas cruzadas e Pontos), Fração volumétrica (Fração de área, } \\
\text { Fração linear e Fração de pontos [Automático e Semiautomático]), Área superficial por unidade } \\
\text { de volume-teste (Automático e Semiautomático), Área superficial específica (Automático e } \\
\text { Semiautomático), Comprimento de intercepto linear por unidade de volume-teste (Automático } \\
\text { e Semiautomático) }\end{array}$ \\
\hline Ajuda & Sobre \\
\hline
\end{tabular}

A barra de ferramentas é composta de diversos botões de acesso rápido. O propósito desta barra é facilitar o uso de recursos essências. Contudo, todas as funcionalidades contidas nesta barra podem ser encontradas na barra de menu. Cabe destacar que o Goitacá inclui um grande número de combinações de teclas de atalhos para facilitar ainda mais sua utilização, como exemplo pode-se citar a combinação das teclas [Ctrl $+\mathrm{S}]$, utilizada para salvar um arquivo.

O painel lateral esquerdo agrupa vários recursos, sendo grupos de cores, fontes, formas, tamanhos, ferramentas e mostrar/ocultar elementos. Além destes recursos, há o player de vídeo que por padrão fica oculto e é exibido quando um arquivo de vídeo é aberto.

A área de trabalho é aquela em que a imagem estática ou dinâmica é exibida. Nesta área podemse inserir diversas anotações gráficas contidas no painel lateral esquerdo, como formas e textos.

No painel de snapshot são exibidas miniaturas de imagens. Cada ação realizada no Goitacá gera um novo snapshot com uma nova miniatura neste painel. Ao clicar em uma destas miniaturas, a ação realizada é desfeita ou refeita. Há ainda a opção do duplo clique na miniatura, que é utilizada para abrir diversas imagens ao mesmo tempo, para fins de comparação de imagens.

A barra de status contém informações significativas, sendo elas posição do pixel (x e y), dimensão da imagem (em pixel e de acordo com a escala definida), tamanho do arquivo e barra de ajuste de zoom.

\subsection{VÍDEO MICROSCOPIA}

O recurso de vídeo microscopia é encontrado geralmente em softwares de análise de imagens comercializados pelos fabricantes de microscópios. É comum que estes softwares carreguem apenas câmeras digitais de mesma marca (AMSCOPE, 2014; LEICA MICROSYSTEMS, 2014; NIKON INSTRUMENTS, 2014). Para a implementação deste recurso, foram utilizados algoritmos genéricos, 
amplamente encontrados na literatura, com intuito de abranger um grande número de modelos de câmeras digitais (BRADSKI; KAEHLER, 2008; INTEL CORPORATION, 2001; OPENCV, 2014).

Foram testados com sucesso cinco modelos de câmeras digitais, sendo dois destes modelos de alta definição e os outros três de câmeras convencionais. Os modelos testados pelo Goitacá são apresentados no

Quadro 4, os dois primeiros modelos são de alta definição e os demais são de câmeras comuns.

Quadro 4 - Lista de câmeras digitais testadas pelo Goitacá.

\begin{tabular}{|l|l|}
\hline Marca & Modelo \\
\hline Microsoft & Webcam Microsoft LifeCam Cinema \\
\hline HP & HP HD Webcam \\
\hline HP & HP Webcam-101 \\
\hline Lenovo & Lenovo EasyCamera \\
\hline Asus & UVC 2M Webcam \\
\hline
\end{tabular}

\subsection{ANOTAÇÕES GRÁFICAS}

As anotações gráficas englobam um grupo de elementos que podem ser inseridos sobre a imagem na área de trabalho, gerando uma nova camada que permite alterar, mover e excluir estes elementos, quando a imagem é salva no formato "goi". Neste grupo constam formas geométricas como círculos, quadrados, triângulos, losangos e hexágonos, além de setas, linhas, linhas livres e textos. Todas estas funções podem ser formatadas em relação aos seus tamanhos, cores, fontes e estilos.

A 
Figura 2 (a) exibe a imagem original. Já a 
Figura 2 (b) ilustra a imagem com anotações gráficas incluídas pelo Goitacá. Nesta figura são incluídos um círculo com uma seta e um texto na cor vermelha, uma figura plana formada por linha livre com uma seta e texto formatado em negrito e itálico na cor preta e um quadrado com uma seta e um texto na cor branca. 


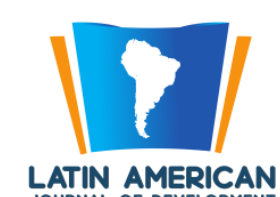

LATIN AMERICAN

Figura 2 - a) Imagem original. b) Imagem com anotações gráficas incluídas pelo Goitacá.

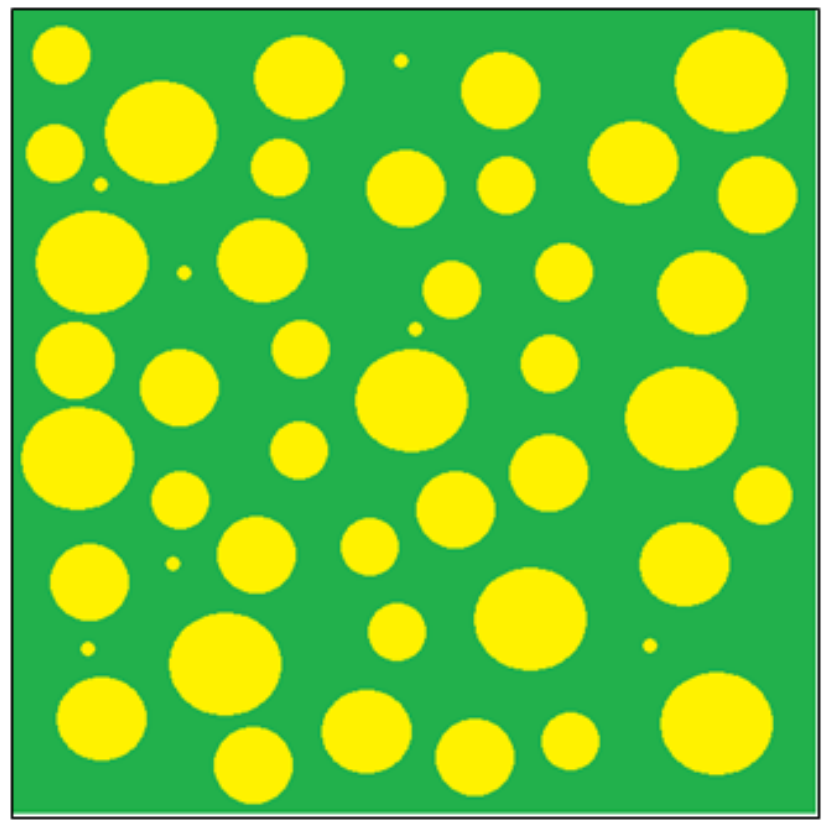

(a)

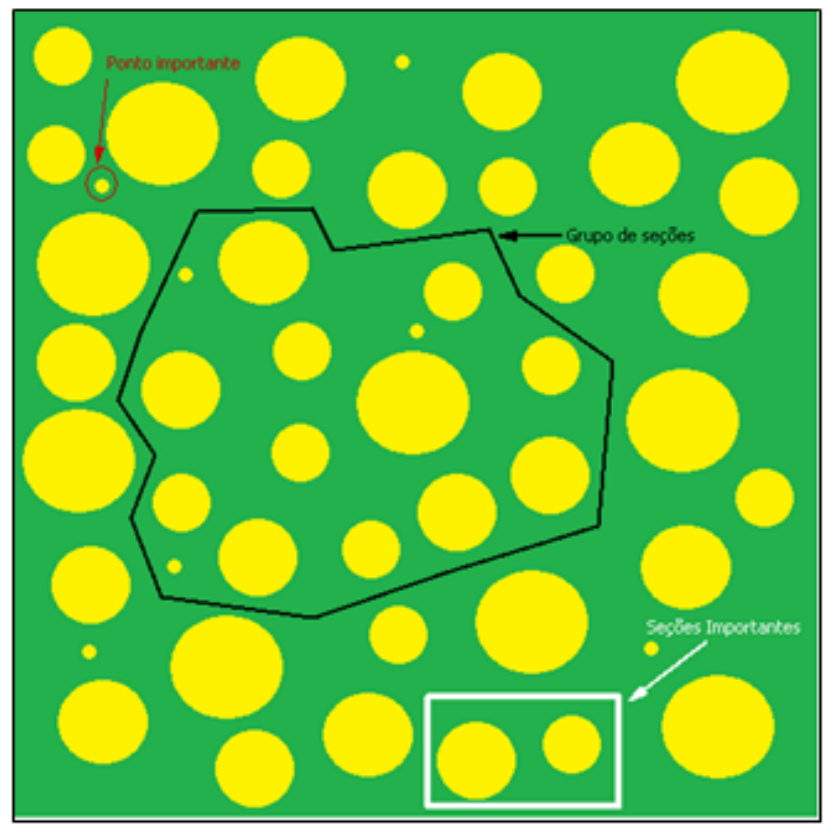

(b)

\subsection{SEGMENTAÇÕES}

As segmentações implementadas no Goitacá são a binarização e a limiarização. Está última é muito incomum inclusive em softwares proprietários, na qual o usuário tem a opção de ajustar um limiar manualmente através das caixas com setas superiores e inferiores ou da barra duplamente ajustável, conforme se observa na Figura 3.

Figura 3 - Tela de limiarização por binarização do Goitacá

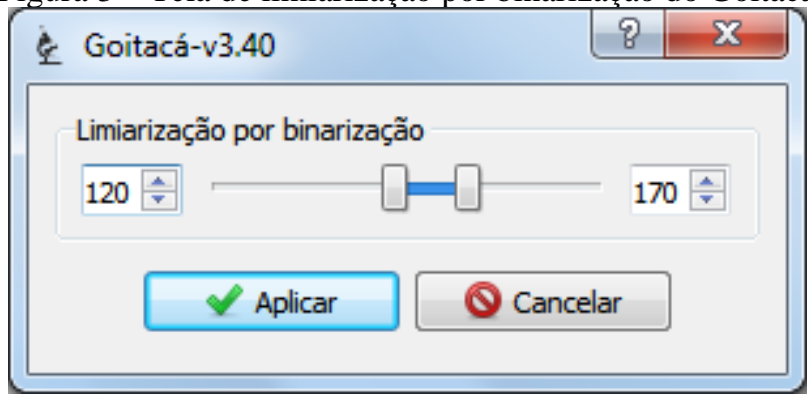

$\mathrm{Na}$ 
Figura 4 (a) é ilustrada a imagem original. Já na 
Figura 4 (b) é exibida a imagem após aplicação da binarização através do limiar especificado na Figura 3. 


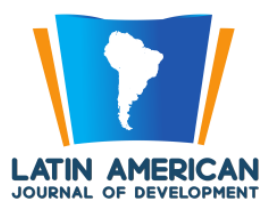

Figura 4 - a) Imagem original. b) Imagem binarizada através dos limiares definidos pelo usuário no Goitacá.

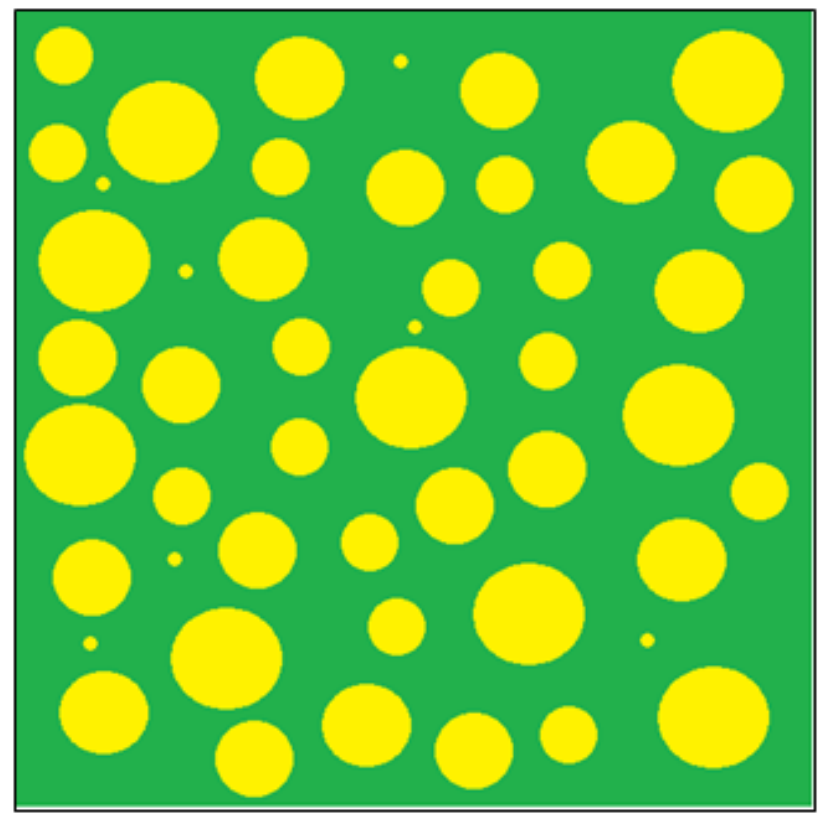

(a)

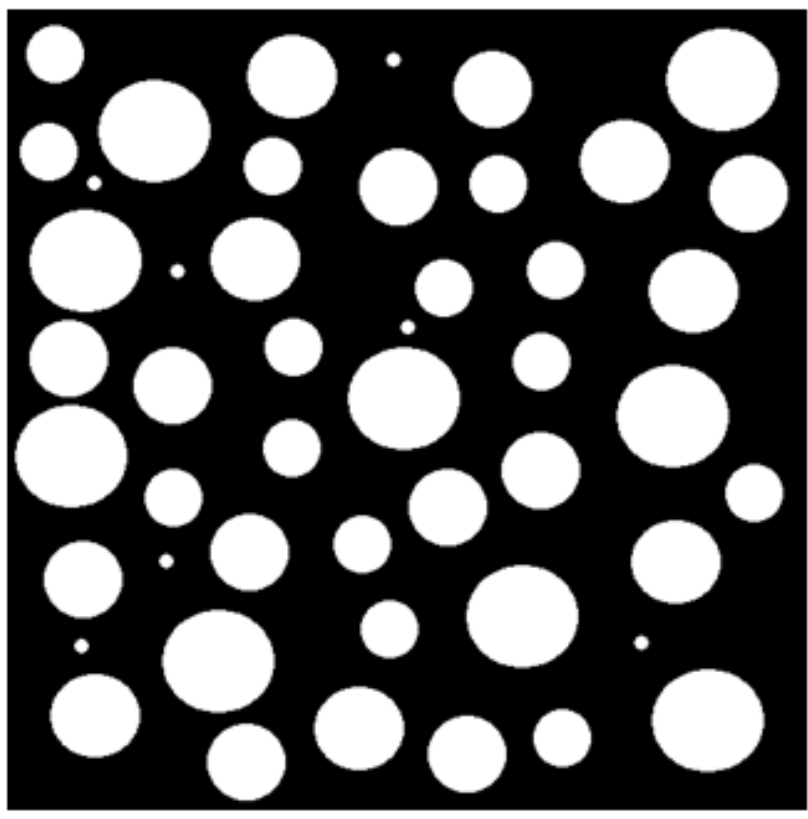

(b)

\subsection{ESCALA}

Para utilizar os recursos de medições de área de região e comprimento entre dois pontos é necessário primeiramente definir a escala no Goitacá. A

Figura 5 ilustra a tela de definição de escala do Goitacá. Nesta tela é necessário a entrada de alguns parâmetros, sendo distância em pixel, distância conhecida e unidade de medida.

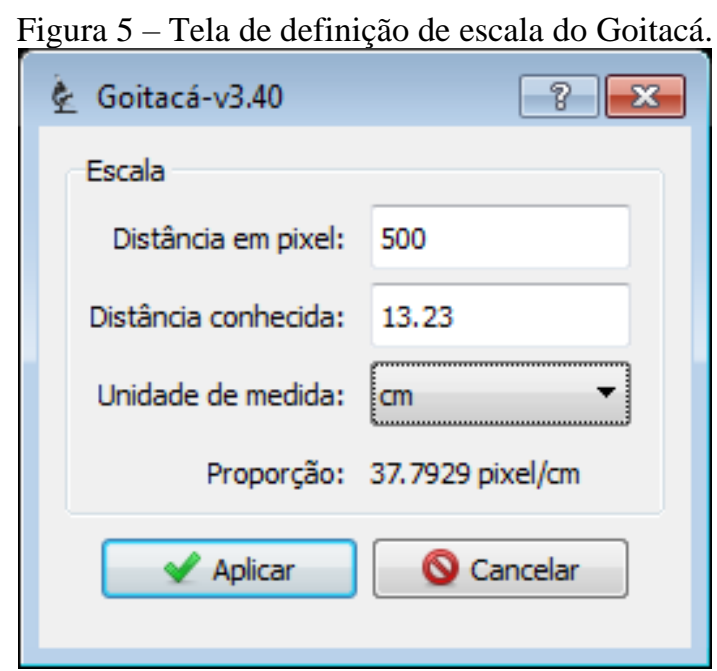

A

Figura 6 (a) exibe a imagem original. Já a 


\section{7 \\ LATIN AMERICAN
JOURNAL OF DEVELOPMENT}

Figura 6 (b) exibe a imagem após a definição da escala pelo Goitacá. Nesta figura são inseridas sobre a imagem duas caixas na cor verde com textos na cor amarelo. A caixa superior direita possui dois valores, o primeiro é a largura real e o segundo é a altura real da imagem, no exemplo tanto um quanto outro são $13,23 \mathrm{~cm}$. Enquanto a caixa inferior esquerda contém uma linha com aproximadamente $10 \%$ da largura da imagem e abaixo o valor desta largura na escala real, neste exemplo o valor é de $1,32 \mathrm{~cm}$.

Figura 6 -a) Imagem original. b) Imagem com escala definida pelo Goitacá.

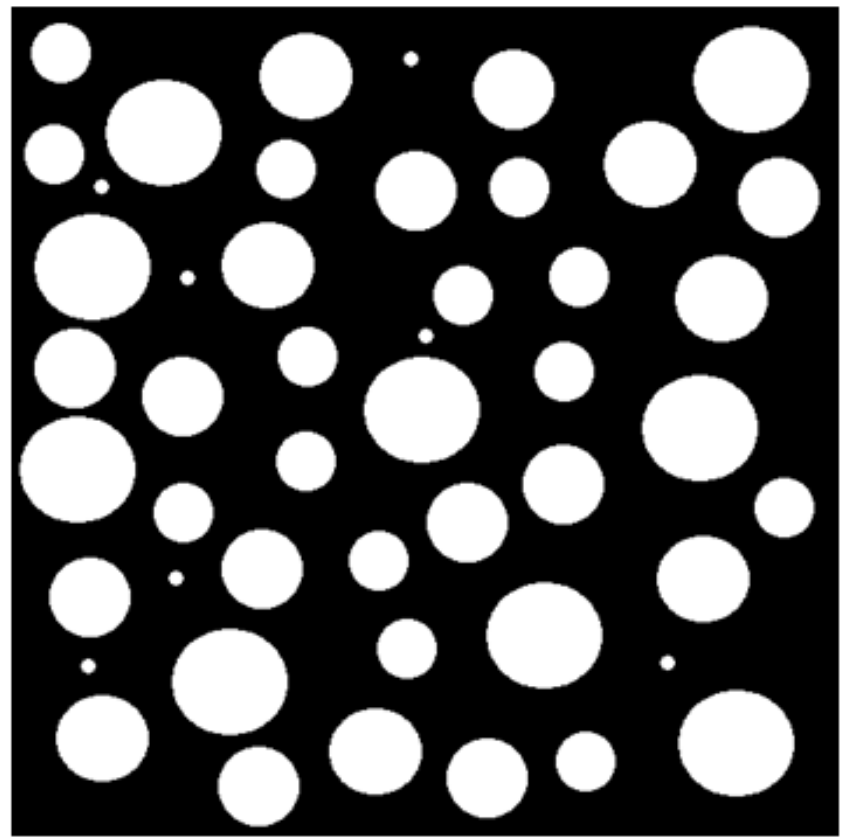

(a)

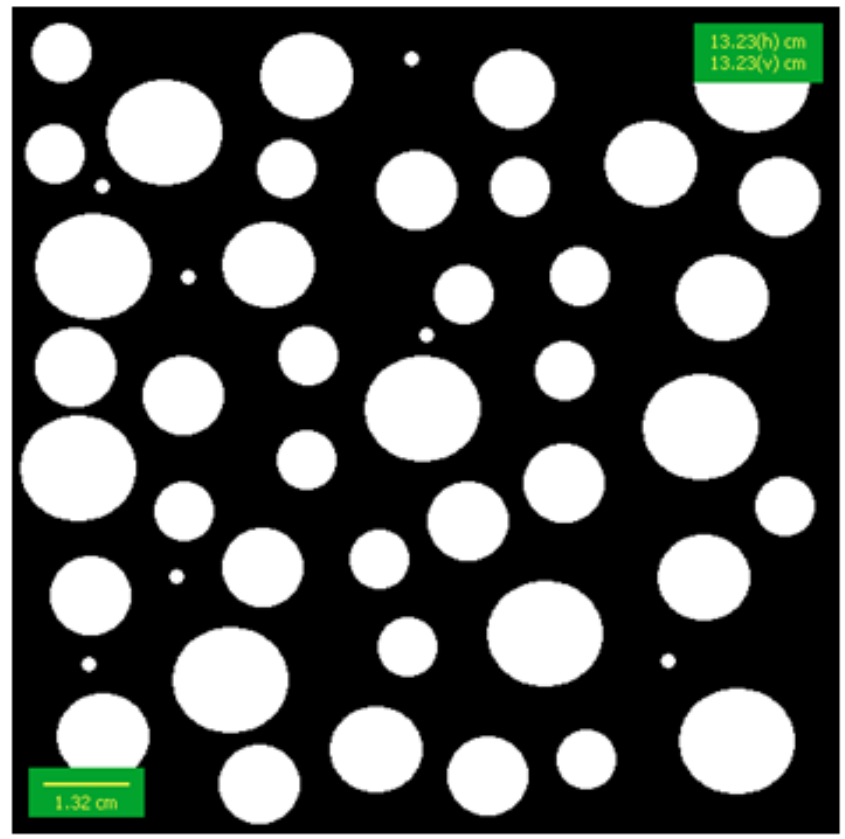

(b)

\subsection{MEDIÇÕES}

O Goitacá possui recursos de medições de ângulos, comprimento entre dois pontos e áreas de região. O recurso de comprimento entre dois pontos é utilizado para calcular a distância na escala real entre um ponto inicial e um final. $\mathrm{Na}$ 
Figura 7 (a) é ilustrada uma imagem binarizada com uma medição de comprimento entre dois pontos realizados pelo Goitacá.

Diversos tipos de áreas de região são medidos pelo Goitacá, sendo elas área de círculo, triângulo, quadrado, losango, pentágono, hexágono e linha livre. Esta última necessita que o usuário inicie e finalize no mesmo ponto a linha livre para criar uma forma plana. A 
Figura 7 (b) demonstra a medição de três áreas de regiões exportadas pelo Goitacá. A primeira delas é formada por uma linha livre na cor verde com área de $307,491 \mathrm{~cm}^{2}$, a segunda delas é um círculo na cor laranja com área de $0,907826 \mathrm{~cm}^{2}$ e por último um quadrado na cor azul com área de $5,32791 \mathrm{~cm}^{2}$. 


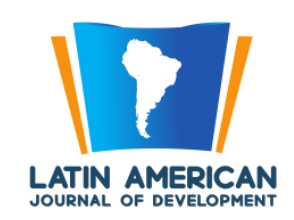

Figura 7 - a) Imagem com medição de comprimento entre dois pontos exportada pelo Goitacá. b) Imagem com medição de áreas de região exportadas pelo Goitacá.

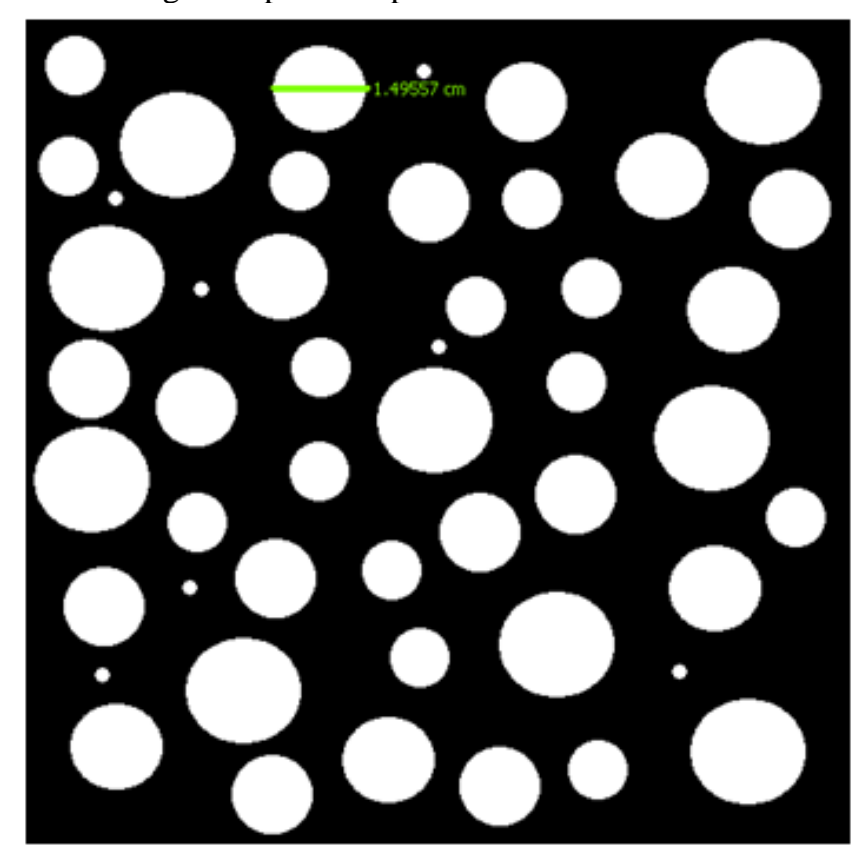

(a)

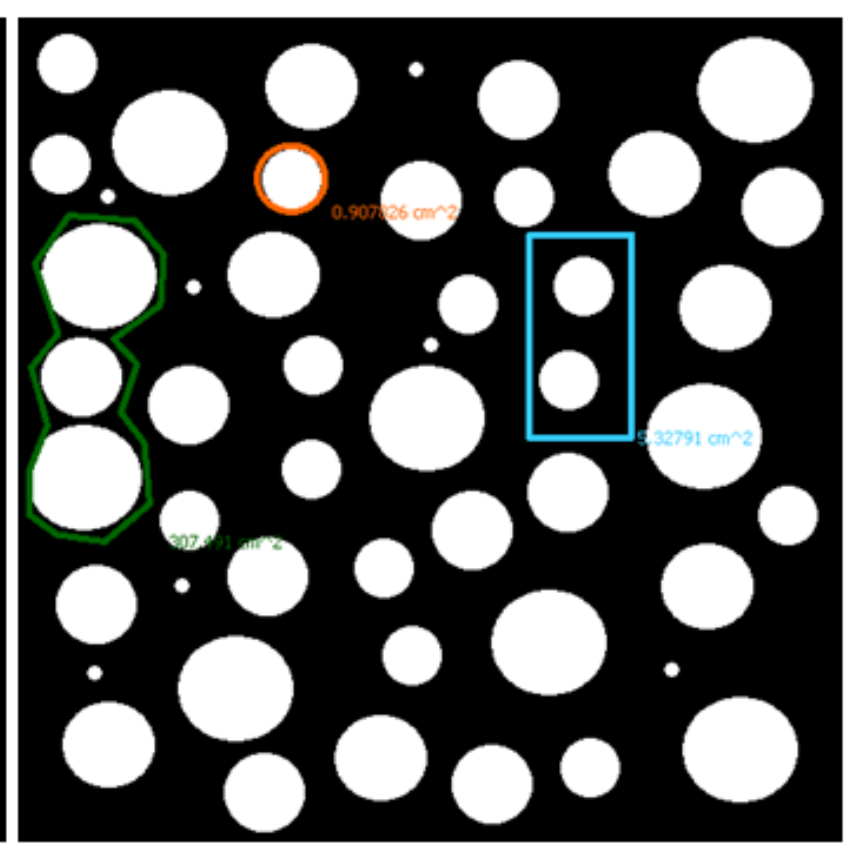

(b)

\section{CONSIDERAÇÕES FINAIS}

Ao final deste trabalho, pode-se concluir que o objetivo foi alcançado, ao passo que se apresenta um produto completo com as características almejadas, e a metodologia de validação foi corretamente conduzida, de modo a confirmar a eficácia da ferramenta.

A pesquisa apontou um nicho acadêmico quando constata que não há o ferramental necessário livremente à disposição do pesquisador para suas investigações científicas, e propõe uma solução integrada de modo a atender pesquisadores e centros de pesquisas que não dispõem de recursos para aquisições de softwares proprietários necessários para algumas medições automatizadas.

Enfim, a ciência e engenharia dos materiais agora incorpora ao arcabouço de recursos para condução de suas pesquisas um software portável, livre, gratuito e válido para as análises de imagens de microscopia ótica. 


\section{REFERÊNCIAS BIBLIOGRÁFICAS}

AMSCOPE. Digital Microscopes, 2014. Disponível em: <http://www.amscope.com>. Acesso em: 7 jan. 2014

BRADSKI, G. R.; KAEHLER, A. Learning OpenCV: computer vision with the OpenCV library. Farnham: O'Reilly, 2008.

DIAS, F. DA C. Uso do software imagej para análise quantitativa de imagens de microestruturas de materiais. Mestrado em Engenharia e Tecnologia Espaciais/Ciência e Tecnologia de Materiais e Sensores-São José dos Campos - SP: Instituto Nacional de Pesquisas Espaciais - INPE, 2008.

FAZANO, C. A. A aplicação da análise de imagem na quantificação das características microestruturais de materiais. Revista Analytica, n. 19, p. 46-60, 2005.

FAZANO, C. A. Determinando-se o tamanho de grãos em ligas de cobre-zinco através da análise de imagem. Revista Analytica, n. 27, p. 50-58, 2007.

FERNANDES, S. M. DE C. et al. Desenvolvimento de um software de análise de imagens para caracterização microestrutural de materiais. Revista Exacta, v. 10, n. 3, p. 325-332, 2012.

IMAGEJ. Image Processing and Analysis in Java, 2014. Disponível em: <http://rsb.info.nih.gov/ij/> . Acesso em: 15 jan. 2014

INTEL CORPORATION. Open Source Computer Vision Library: Reference Manual, 2001. Disponível em: <http://itee.uq.edu.au/ iris/CVsource/OpenCVreferencemanual.pdf>. Acesso em: 6 jan. 2014

LASEROPTICS. VideoMicroscopia, 2014. Disponível em: <http://www.laseroptics.com.ar/videomicroscopia.htm>. Acesso em: 7 jan. 2014

LEICA MICROSYSTEMS. Leica LAS Interactive Measurement, 2014. Disponível em: <http://www.leica-microsystems.com/products/microscope-software/materialssciences/details/product/leica-las-interactive-measurement/>. Acesso em: 9 jan. 2014

MENDES, S. C. C. M. Eléctrodos de filme fino de mercúrio para análise de metais vestigiais estudos de optimização, caracterização e modificação química com poli(4-estirenosulfonado de sódio). Tese de Doutorado em Química-Aveiro - PT: Universidade de Aveiro - UA, 2005.

NIKON INSTRUMENTS. Sistemas de Microscópio, 2014. Disponível em: <http://www.nikoninstruments.com/pr_BR/Produtos/Sistemas-de-Microscopio/>. Acesso em: 7 jan. 2014 
NOGUEIRA, I. L. Desenvolvimento de software para identificação e caracterização de pites de corrosão em cupons. Mestrado em Engenharia e Ciência dos Materiais-Campos dos Goytacazes RJ: Universidade Estadual do Norte Fluminense - UENF, 2013.

OPENCV. Open Source Computer Vision, 2014. Disponível em: <http://opencv.org/>. Acesso em: 15 jan. 2014 